\title{
Do Breast Cancer Patients Tested in the Oncology Care Setting Share BRCA Mutation Results with Family Members and Health Care Providers?
}

\author{
Susan T. Vadaparampil, ${ }^{1,2}$ Teri Malo, ${ }^{1}$ Cara de la Cruz, ${ }^{1}$ and Juliette Christie ${ }^{1}$ \\ ${ }^{1}$ Health Outcomes and Behavior Program, Division of Cancer Prevention and Control, Moffitt Cancer Center, \\ 12902 Magnolia Drive, Tampa, FL 33612, USA \\ ${ }^{2}$ Department of Oncologic Science, College of Medicine, University of South Florida, \\ 12901 Bruce B. Downs Boulevard, Tampa, FL 33612, USA
}

Correspondence should be addressed to Susan T. Vadaparampil, susan.vadaparampil@moffitt.org

Received 2 April 2012; Accepted 25 May 2012

Academic Editor: Laura Koehly

Copyright (๑) 2012 Susan T. Vadaparampil et al. This is an open access article distributed under the Creative Commons Attribution License, which permits unrestricted use, distribution, and reproduction in any medium, provided the original work is properly cited.

$B R C A$ genetic test results provide important information to manage cancer risk for patients and their families. Little is known on the communication of genetic test results by mutation status with family members and physicians in the oncology care setting. As part of a longitudinal study evaluating the impact of genetic counseling and testing among recently diagnosed breast cancer patients, we collected patients' self-reported patterns of disclosure. Descriptive statistics characterized the sample and determined the prevalence of disclosure of BRCA test results to family members and physicians. Of 100 patients who completed the baseline and the 6-month followup survey, 77 reported pursuing testing. The majority shared test results with female first-degree relatives; fewer did with males. Participants were more likely to share results with oncologists compared to surgeons, primary care physicians, or other specialty physicians. These findings suggest that while breast cancer patients may communicate results to at-risk female family members and their medical oncologist, they may need education and support to facilitate communication to other firstdegree relatives and providers.

\section{Introduction}

Mutations in the BRCA1 and BRCA2 (BRCA) genes place individuals at higher risk of developing breast and ovarian cancer, compared to those without a mutation $[1,2]$. A recent study of cancer risks in $B R C A$ mutation carriers in a large US-based sample estimated the cumulative breast cancer risk at age 70 years to be $46 \%$ in BRCA1 carriers and $43 \%$ in $B R C A 2$ carriers. Cumulative ovarian cancer risk was $39 \%$ in BRCA1 carriers and $22 \%$ in BRCA2 carriers [3]. Although less well-established, elevated cancer risks in men from $B R C A$ families have been reported in male breast cancer $(6-8 \%)[4-10]$ and prostate cancer $(20-30 \%)[5,8,10-27]$. Individuals who undergo genetic testing and discover that they carry a $B R C A$ mutation can manage their cancer risk through intensive screening, prophylactic surgery, and/or chemoprevention [28-31]. Criteria set forth by the National
Comprehensive Cancer Network to identify and refer breast cancer patients to a genetics professional [32] include a personal history of early onset breast cancer (i.e., diagnosed $\leq$ age 50), triple negative breast cancer, and/or $\geq 2$ primary cancers. Women diagnosed with breast cancer at any age may also be referred when there is a family history of early onset breast cancer, ovarian cancer at any age, and/or male breast cancer. Additionally, women with a family history of breast cancer and cancers considered to be part of the Hereditary Breast Ovarian Cancer spectrum (e.g., pancreatic, thyroid) may also warrant genetic evaluation.

Clinical guidelines indicate the most informative clinical testing strategy is to first test a family member with cancer [33]. Then, if a familial mutation is identified, testing can be offered to unaffected family members to determine whether they have the already identified BRCA mutation [33]. If there 
was a previously identified mutation in the family and the proband's test way negative (i.e., true negative), the proband generally is considered to be at general population risk for cancer. In this situation, there is a high level of reassurance that BRCA mutations are not the underlying cause of cancer, which may reduce anxiety as well as unnecessary screening and surveillance in the proband and at-risk family members. Conversely, test results are considered uninformative if an individual is the first person in the family to have testing and receives a negative result or if an alteration in the $B R C A$ genes is detected but the clinical significance for the alteration is unknown (i.e., variant of uncertain significance). In this situation, cancer risk is determined based on personal and family cancer history.

In order for genetic test results to maximally benefit and impact clinical management, test results must be communicated to others. To impact the health of family members, probands must share results with at-risk relatives [34]. For management of the proband's personal cancer risk, healthcare providers must also be aware of test results. The healthcare system's emphasis on patient confidentiality, clinical practices in which genetic testing results may not be included as part of the "main" medical record, and position statements from professional organizations such as the American Society of Clinical Oncology [35] and the American Society of Human Genetics [36] indicating that providers generally do not share genetic testing information and results with family members who are not their patients may limit the ability of providers to participate in dissemination of test results among family members. As such, the responsibility of communicating BRCA test results likely falls on the probands themselves. Prior studies of communication of test results to family members have found that the majority of participants share test results with family members, typically within the first few months of receiving test results. However, frequency of disclosure may vary based on test result as well as the family members' age, gender, and degree of relatedness (e.g., first-degree versus second-degree relative) [37-48]. Qualitative and quantitative studies also demonstrate that probands sometimes express difficulty in sharing results with at-risk relatives, particularly when relationships are emotionally distant or test results are uninformative $[43,44,49]$.

An understudied aspect of communication regarding $B R C A$ test results is whether results are shared with individuals outside of the family structure, namely, health care providers. Given that probands are often identified due to a personal cancer diagnosis and subsequently receive counseling and testing in the oncology care setting, it is important that as they transition into survivorship and shift health care back into the community setting, primary care providers are also made aware of $B R C A$ test results $[50,51]$. Despite the important role that health care providers play in providing care to patients based on $B R C A$ test results, only two studies have examined communication of $B R C A$ test results to health care providers. In a study of 69 patients referred to a cancer risk assessment program, the majority of patients shared results with both oncology (64-88\%) and primary care providers (74-81\%) [50]. In a larger study of 312 patients who underwent $B R C A$ testing at a large comprehensive cancer center, most $(72 \%)$ shared genetic test results with health care providers outside of the oncology care setting [51].

Some data suggest patients affected with cancer may react differently than unaffected probands to the cancer genetic counseling and testing process [52-54] including communication of test results $[40,51,55]$. It is possible that having genetic counseling and testing following a cancer diagnosis may delay or reduce the likelihood that patients disseminate test results to at-risk family members due to both the physical and emotional stressors of diagnosis and treatment. Despite the arguable equal importance of affected probands sharing test results with both at-risk family members and health care providers, to our knowledge, no prior study has examined disclosure patterns to family members and physicians in a group of affected patients in a single study. To that end, the primary focus of our paper is to describe the frequency of communication of test results among breast cancer patients who have undergone genetic counseling and testing in the breast oncology care setting. The findings from this study will inform the development of comprehensive interventions that facilitate communication of test results by probands to both family members and health care providers.

\section{Method}

2.1. Participant Recruitment. This substudy regarding communication of BRCA test results is part of a larger longitudinal investigation of the impact of genetic counseling on psychosocial and behavioral outcomes among breast cancer patients referred for genetic counseling in the oncology care setting. Eligibility criteria for the larger study included: (a) meeting National Comprehensive Cancer Network cancer genetics referral criteria [32], (b) $\geq 18$ years of age; (c) confirmed personal breast cancer diagnosis based on medical records review; (d) no previous participation in genetic counseling (GC) and/or testing for hereditary breast and ovarian cancer (HBOC); (e) capable of speaking and reading standard English; (f) having a mailing address and working telephone number; and (g) having a GC appointment scheduled at Moffitt Cancer Center.

Upon Institutional Review Board approval, recruitment took place between April 2009 and July 2010 with followup completed in February 2011. Data were collected: (a) after scheduling but prior to the pretest genetic counseling appointment (T1), (b) within two to three weeks after participants completed pretest genetic counseling (T2), and (c) six months after completing genetic testing (T3). The current report is focused on the communication of $B R C A$ mutation test results; therefore, analyses are based on T1 (sociodemographic and clinical) and T3 (communication of test results) data.

All patients in the current study received in-person pretest GC by a Masters-level prepared genetic counselor through the clinical GC and testing service at the Cancer Center. For those who proceeded with testing, the majority received testing by the sole clinical laboratory for $B R C A$ 
testing in the US. Those who were uninsured or unable to obtain insurance coverage for testing were informed of a research study at another institution where they were able to receive $B R C A$ testing free of charge. Those who proceeded with testing were subsequently scheduled for either an inperson or telephone-based posttest results disclosure session. Those patients then received followup letters summarizing their pre- and posttest GC sessions.

The study team reviewed the GC appointment schedule weekly for women meeting study eligibility criteria. Eligible patients were mailed an introductory letter with a toll-free number to opt out of further contact by the study team, the T1 survey, two consent forms, and a preaddressed envelope. Approximately one week from the mailing date, patients who did not opt out were contacted via telephone to confirm receipt of study materials and to answer any questions about the study. For those not reachable by telephone prior to their scheduled GC appointment, the study coordinator met briefly with patients after their GC session to determine whether the T1 survey was complete. Those who did not complete the T1 survey before attending their pretest GC session were considered decliners.

For the first six weeks of study recruitment, patients who failed to attend their pretest GC appointment were considered ineligible. However, this strategy precluded the opportunity to include patients who rescheduled and attended their GC appointment. Thus, recruitment procedures were revised so that patients who scheduled a new appointment were mailed an additional introductory study packet. Patients who failed to reschedule their appointment between the date of their canceled appointment and July 2010 (end of recruitment period) were considered ineligible. Participants received a $\$ 25.00, \$ 20.00$, and $\$ 30.00$ gift card for completing $\mathrm{T} 1, \mathrm{~T} 2$, and T3, respectively. Those patients who completed the T1 and T3 assessments and reported BRCA genetic test results were included in the current analyses.

\section{Measures}

Sociodemographic and clinical characteristics obtained from patient questionnaires or medical records review included: current age, age at diagnosis, time since diagnosis, current stage of breast cancer $(1,2 / 3,4$, unstaged, other [e.g., unknown]), previous surgery (yes, no), and primary payor at diagnosis (private insurance, public insurance, no insurance, other). In addition, we classified BRCA mutation status as: positive, true negative (i.e., tested negative for known familial $B R C A$ mutation), and uninformative (tested negative in the absence of a known familial BRCA mutation or had an indeterminate or variant of uncertain significance result). We excluded 15 people who indicated they either did not know or had an "other" test result from the analyses examining disclosure of test results to family members and physicians. Additional data collected via selfreport questionnaires included: education (completed high school or less; vocational school and some college; college graduate and beyond), total household income at time of diagnosis $(\leq 35,000 ;>35-\leq 50,000 ;>50,000)$, marital status (married/living with partner, other), and race (Black, White, other).

Family communication of BRCA test results was assessed using an abbreviated version of the Family Communication Measure, developed by Patenaude and colleagues [43]. Respondents were asked to complete the following information for each first-degree relative : relative still living (yes, no), age, and status of result disclosure (shared, did not share).

Communication of results to health care providers was assessed with a single item developed for the current study where participants were first asked whether they shared their results with a health care provider (yes, no, do not know). Those who responded "yes" were asked to select the specialties for each of the providers with whom they shared the information (surgeon, oncologist, obstetrician/gynecologist [OBGYN], primary care doctor, doctor of another specialty, or other health care provider).

3.1. Data Analysis. Descriptive statistics were calculated to characterize the sample and to determine the prevalence of disclosure of $B R C A$ test results to family members and physicians. To determine the prevalence of BRCA-test result disclosure, the proportions of living relatives with whom test results were shared stratified by family member (e.g., mother) and participant BRCA status (positive, true negative, uninformative) were calculated. Statistical analyses were conducted using SAS (Version 9.2, Cary, NC).

\section{Results}

As shown in Figure 1, a total of 223 patients were identified by the genetic counselor as potential participants who had scheduled an appointment for GC. Of these, 87 patients did not meet eligibility requirements (e.g., previous participation in GC and/or testing for HBOC, rescheduled GC appointment more than three times, nonEnglish speaking). Of the remaining 136 eligible participants, 114 consented and completed the T1 survey, resulting in an $83.8 \%$ response rate. Of those 114, 100 completed the T3 assessment that included questions about communication of test results. Data analyses were conducted on 77 women who reported pursuing $B R C A$ testing.

As detailed in Table 1, study participants were on average 48 years old at the time of diagnosis. At the time of the T1 survey, participants were on average 52 years old and a median of 9.7 months had passed since they were diagnosed. The majority was married or living with a partner $(66.2 \%)$; white $(81.8 \%)$; at least a college graduate $(46.8 \%)$; and covered by private insurance $(57.1 \%)$. The greatest proportion had an annual household income of more than $\$ 50,000$ at the time of diagnosis (39.0\%). Regarding clinical variables, the greatest proportion of participants $(31.2 \%)$ were in stage 2 or 3 and the vast majority $(83.1 \%)$ had previous surgery for their breast cancer. In terms of $B R C A$ test result, $40.3 \%$ had a true negative result, $3.9 \%$ tested positive, and $14.3 \%$ had an uninformative result. 


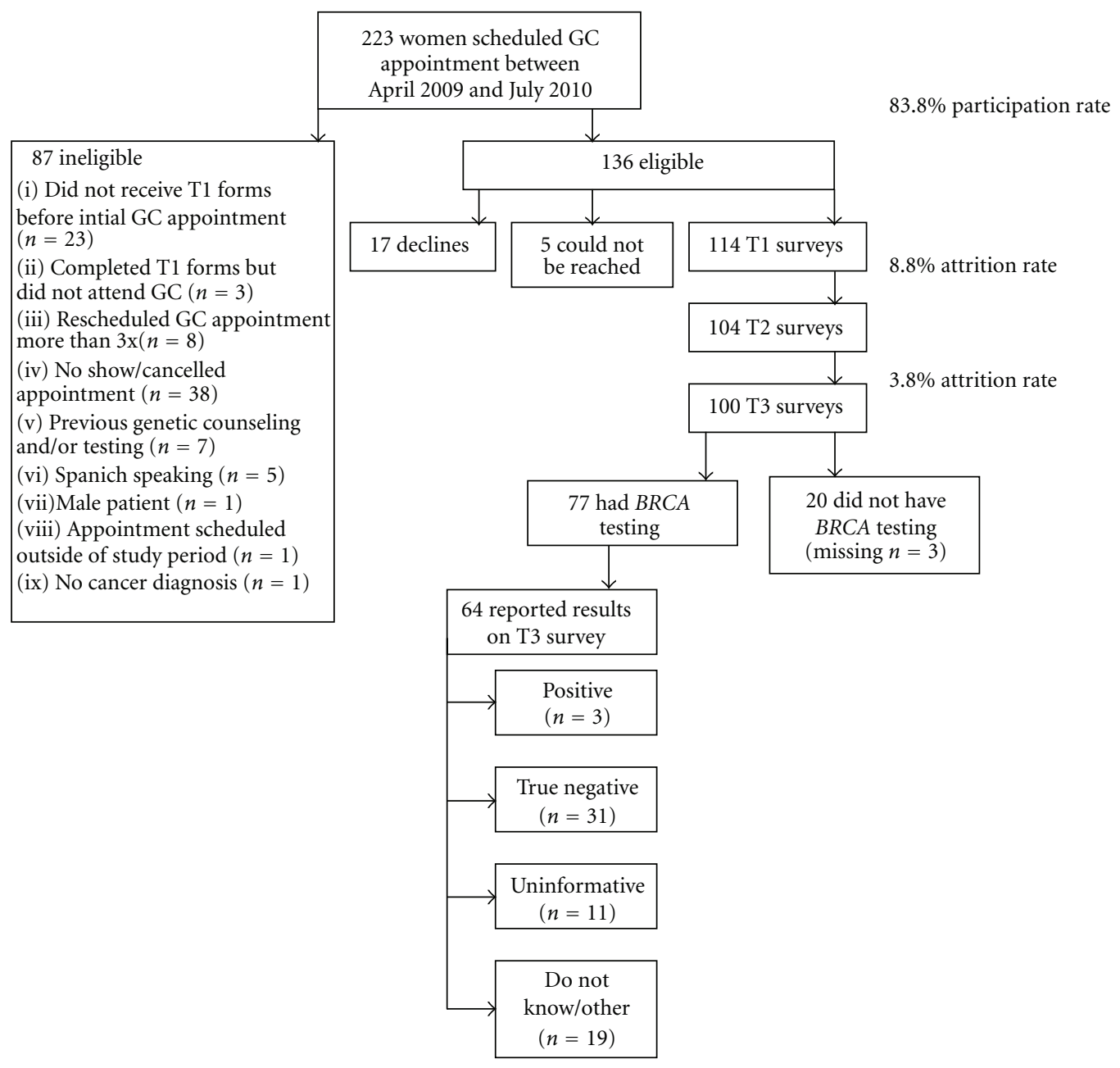

Figure 1: Study flow diagram.

As seen in Table 2, most probands communicated results with family members, regardless of the test results. Of participants who tested positive $(n=3)$, all shared their test results with their mothers, fathers, and sisters, whereas participants shared with half of daughters aged 18 or older and brothers, on average. Of those who tested true negative $(n=31)$, sharing of results with first-degree relatives ranged from an average of only $67 \%$ of daughters younger than age 18 up to $100 \%$ of sons younger than 18. Participants with uninformative results $(n=11)$ shared results with all sons or daughters age 18 years or older. In general, a greater proportion of participants reported sharing their test result with all female relatives compared to male relatives. Participants who tested true negative reported sharing results with an average of $90-100 \%$ of female relatives aged 18 or older compared to $83-89 \%$ of male relatives. Those with an uninformative result shared with an average of $80-100 \%$ of female adult relatives compared to $56-100 \%$ of male adult relatives. Regarding disclosure to minor children (age 18 years or younger), those who tested true negative shared their result with an average of $67 \%$ of minor daughters and $100 \%$ of minor sons. Those with an uninformative test result shared with half of minor daughters and none of minor sons. Figure 2 summarizes patients' reports of communication of genetic test results with health care providers. Overall, 74\% shared their test results with their oncologist and 51\% with their surgeon. They were less likely to share results with their primary care physicians (40\% of OBGYNs and $49 \%$ of primary care physicians) or other specialty physicians (9\%).

\section{Discussion}

Overall, our study suggests that frequency of disclosure of genetic test results by probands varies by mutation status, gender of at-risk relatives, and age of at-risk relatives. For health care providers, disclosure rates varied by specialty.

Although based on a limited sample size, our findings suggest variability in disclosure patterns based on mutation status. Women who tested positive were most likely to communicate results to both parents and all sisters (100\%), compared to those who tested true negative or uninformative. It is possible that the differences between positives and true negatives may be due to the fact that women who were in the true negative category were being tested for a previously 
TABLE 1: Sociodemographic and clinical characteristics of study participants who had BRCA testing $(n=77)^{\mathrm{a}}$.

\begin{tabular}{|c|c|}
\hline Characteristic & Mean (SD, range) \\
\hline Age at diagnosis (years) & $47.6(10.7,24-69)$ \\
\hline Current age (years) & $52.0(10.9,25-70)$ \\
\hline \multirow[t]{2}{*}{ Time since diagnosis (months) } & $44.5(70.2,0.6-339.9)$ \\
\hline & $n(\%)$ \\
\hline \multicolumn{2}{|l|}{ Current stage } \\
\hline Stage 1 & $19(24.7)$ \\
\hline Stage $2 / 3$ & $24(31.2)$ \\
\hline Stage 4 & $6(7.8)$ \\
\hline Unstaged & $7(9.1)$ \\
\hline Other/unknown & $14(18.2)$ \\
\hline \multicolumn{2}{|l|}{$B R C A$ test result } \\
\hline Positive & $3(3.9)$ \\
\hline True negative & $31(40.3)$ \\
\hline Uninformative & $11(14.3)$ \\
\hline Do not know/other & $19(24.7)$ \\
\hline Did not report result & $13(16.9)$ \\
\hline \multicolumn{2}{|l|}{ Previous surgery } \\
\hline Yes & $64(83.1)$ \\
\hline No & $9(11.7)$ \\
\hline \multicolumn{2}{|l|}{ Primary payor at diagnosis } \\
\hline Private insurance & $44(57.1)$ \\
\hline Public insurance & $18(23.4)$ \\
\hline No insurance & $2(2.6)$ \\
\hline Other & $11(14.3)$ \\
\hline \multicolumn{2}{|l|}{ Education } \\
\hline High school or less & $13(16.9)$ \\
\hline Vocational school/some college & $25(32.5)$ \\
\hline College graduate and beyond & $36(46.8)$ \\
\hline \multicolumn{2}{|c|}{ Total household income prior to diagnosis } \\
\hline$\leq 35 \mathrm{~K}$ & $20(26.0)$ \\
\hline$>35 \mathrm{~K}$ to $\leq 50 \mathrm{~K}$ & $12(15.6)$ \\
\hline$>50 \mathrm{~K}$ & $30(39.0)$ \\
\hline Prefer not to answer & $14(18.2)$ \\
\hline \multicolumn{2}{|l|}{ Marital status } \\
\hline Married or living with partner & $51(66.2)$ \\
\hline Other & $26(33.8)$ \\
\hline \multicolumn{2}{|l|}{ Race } \\
\hline White & $63(81.8)$ \\
\hline Black & $5(6.5)$ \\
\hline Other & $6(7.8)$ \\
\hline
\end{tabular}

${ }^{a}$ Percentages may not add up to 100 due to missing data.

identified mutation in the family. Thus, some parents and sisters may have already been tested, making it less likely that patients would see the need to disclose test results to other relatives who already have definitive information about their mutation status. This explanation is supported by the observation that those who were true negative were more likely to share results with brothers and children (i.e., those not likely to have had prior testing) when compared to those

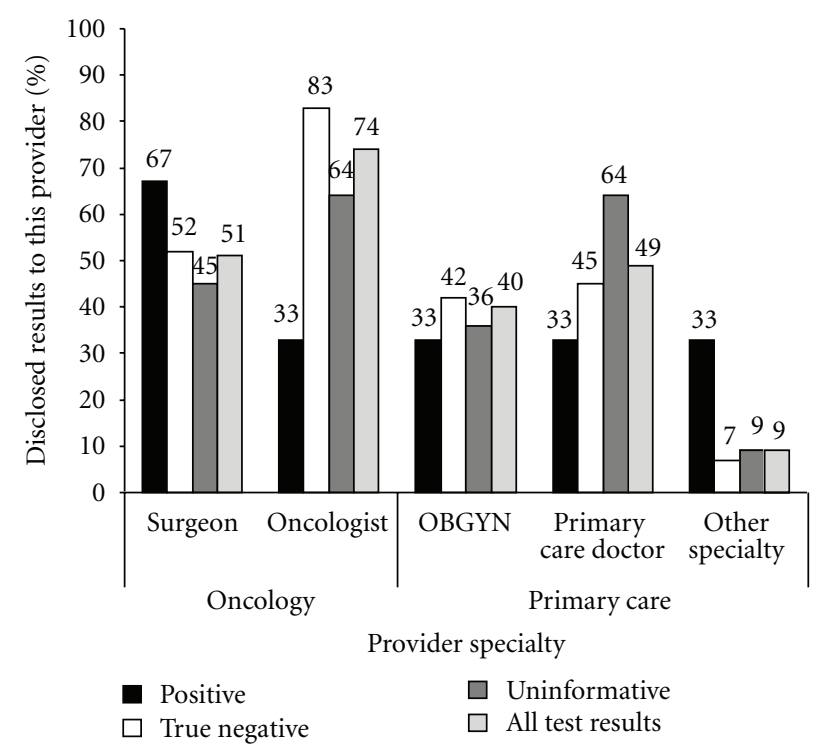

Figure 2: Patients' report of sharing test results by provider specialty and mutation status.

who tested positive. It is also possible that those who test negative for a known familial mutation may feel a sense of guilt in sharing results with relatives who are positive (most likely parents or sisters who have been tested) $[56,57]$.

Similar to prior studies [43], those who received uninformative results were also less likely to share results with family members compared to those who tested positive. Women with these test results may have difficulty understanding and communicating test results to family members due to both cognitive and emotional factors. A few studies of women who received uninformative test results suggest that they are likely to express uncertainty, misinterpret their test results $[58,59]$, or report negative emotional reactions such as anger and frustration [59]. Communication of uninformative test results may occur less often because of probands'concern that at-risk relatives would take the results to mean they were not at increased risk for breast cancer [42]. This is evidenced by a recent study of 39 relatives of probands who received uninformative test results; relatives' medical decisions were based on their own perceptions of increased cancer risk and generally did not correlate with information actually communicated to them by the proband [34].

As observed in prior studies [43, 45, 46, 48, 55], probands were more likely to disclose test results to female relatives in each test result category. This finding is likely due to the higher cancer risks and greater availability of prevention/risk management options for female patients. However, given the equal risks of transmitting $B R C A$ mutations to male and female offspring, increasing documentation of male cancer risks [60], and emerging surveillance guidelines for male $B R C A$ mutation carriers [61], it is critical that female patients understand the importance of sharing test results with all atrisk relatives.

Another interesting observation from our study that is consistent with recent investigations on this topic is the 
TABLE 2: Frequency of sharing test results with first-degree relatives by mutation status.

\begin{tabular}{|c|c|c|c|c|}
\hline \multirow{2}{*}{ Relationship } & & \multicolumn{3}{|c|}{ Shared results $n(\%)$} \\
\hline & & $\begin{array}{c}\text { Positive } \\
(n=3) n \text { or \% (range) }\end{array}$ & $\begin{array}{c}\text { True negative } \\
(n=31) n \text { or } \%(\text { range })\end{array}$ & $\begin{array}{c}\text { Uninformative } \\
(n=11) n \text { or } \% \text { (range) }\end{array}$ \\
\hline \multirow{4}{*}{ Parent } & Mother $(n=16)$ & $n=1$ & $n=10$ & $n=5$ \\
\hline & $n(\%)$ & $1(100.0)$ & $9(90.0)$ & $4(80.0)$ \\
\hline & Father $(n=19)$ & $n=1$ & $n=12$ & $n=6$ \\
\hline & $n(\%)$ & $1(100.0)$ & $10(83.3)$ & $4(66.7)$ \\
\hline \multirow{6}{*}{ Sibling } & Sister $(n=23)$ & $n=2$ & $n=14$ & $n=7$ \\
\hline & Avg. number per participant & $1.5(1.0-2.0)$ & $1.6(1.0-4.0)$ & $2.1(1.0-4.0)$ \\
\hline & Avg. \% disclosed & $100.0(100.0-100.0)$ & $92.9(0.0-100.0)$ & $91.7(66.7-100.0)$ \\
\hline & Brother $(n=22)$ & $n=2$ & $n=16$ & $n=4$ \\
\hline & Avg. number per participant & $2.0(1.0-3.0)$ & $1.6(1.0-4.0)$ & $2.0(1.0-4.0)$ \\
\hline & Avg. \% disclosed & $50.0(0.0-100.0)$ & $89.1(0.0-100.0)$ & $56.3(0.0-100.0)$ \\
\hline \multirow{14}{*}{ Child } & Daughter & & & \\
\hline & $<18$ years $(n=4)$ & $n=0$ & $n=3$ & $n=1$ \\
\hline & Avg. number per participant & - & $1.3(1.0-2.0)$ & $2.0(-)$ \\
\hline & Avg. \% disclosed & - & $66.7(0.0-100.0)$ & $50.0(-)$ \\
\hline & $18+$ years $(n=19)$ & $n=2$ & $n=12$ & $n=5$ \\
\hline & Avg. number per participant & $1.5(1.0-2.0)$ & $1.3(1.0-2.0)$ & $1.4(1.0-2.0)$ \\
\hline & Avg. \% disclosed & $50.0(0.0-100.0)$ & $100.0(100.0-100.0)$ & $100.0(100.0-100.0)$ \\
\hline & Son & & & \\
\hline & $<18$ years $(n=7)$ & $n=0$ & $n=5$ & $n=2$ \\
\hline & Avg. number per participant & - & $1.0(1.0-1.0)$ & $2.0(2.0-2.0)$ \\
\hline & Avg. \% disclosed & - & $100.0(100.0-100.0)$ & $0.0(0.0-0.0)$ \\
\hline & $18+$ years $(n=15)$ & $n=0$ & $n=9$ & $n=6$ \\
\hline & Avg. number per participant & - & $1.4(1.0-3.0)$ & $1.7(1.0-3.0)$ \\
\hline & Avg. \% disclosed & - & $83.3(0.0-100.0)$ & $100.0(100.0-100.0)$ \\
\hline
\end{tabular}

*Excluded those who did not share their results.

*Analyses are based on living relatives and include participants who reported at least one living relative in each relationship category.

disclosure of test results to minor children. While there are specific recommendations against $B R C A$ testing for minors $[35,62]$, there are less clear guidelines regarding disclosure of parents' test results to children. Because there are no recommended surveillance or risk reduction options prior to age 25 for known BRCA mutation carriers, there has been debate about the possible negative sequelae associated with disclosing cancer risk to minor children. Yet, several studies have documented that parents share test results with their minor offspring [37, 38, 63-65]. In our study, of the three women with positive $B R C A$ test results, none had a daughter or son below the age of 18 . Those who tested true negative shared results with an average of $67 \%$ of minor daughters and shared uninformative test results with at least one daughter. The largest published study to date on this topic included 253 parents who had undergone BRCA testing and 505 offspring. Not surprisingly, for those who shared true negative results, children often expressed relief. However, parents perceived distress more frequently among offspring learning about their parent's BRCA positive or variant of uncertain significance result [38]. Thus, consideration of developmentally appropriate psychosocial interventions to support children who learn of BRCA mutation status, particularly positive and uninformative results, is warranted.

With regard to sharing results with health care providers, it appears that women were more likely to share results with oncology care providers, particularly medical oncologists. Prior studies document that fewer women attend GC (and therefore pursue testing) prior to surgical treatment for breast cancer $[66,67]$. Thus, the sharing of results with medical oncologists likely reflects the greater proportion of women referred by medical oncologists who generally assume their care after surgery. This finding is also supported by several studies of provider utilization of GC and testing that suggest when compared to other oncology care physicians (e.g., surgeons, radiation oncologists), medical oncologists have higher levels of knowledge and utilization of BRCA testing [68-70]. It is possible that the rates of sharing results with providers in the oncology care setting may also reflect probands' assumptions that all providers from a single institution would be made aware of or have access to genetic test results. However, at some institutions, $B R C A$ results may be kept out of the "main" medical record and not accessible to all physicians involved in a patient's 
oncology care [71]. The health professional providing preand posttest GC should also discuss the patient's preferences for informing the relevant oncology providers based on specific institutional policies about documentation of $B R C A$ test results.

Overall, participants reported sharing test results less often with primary care providers compared to oncology care providers. The frequency of sharing results (40-49\%) is similar to another study that examined sharing of $B R C A$ genetic test results with nononcology health care providers (30-44\%) [51]. It is noteworthy that although patients in our study were only $\sim 5$ months from receiving test results, compared to the other study where participants may have been several years from testing (as early as 1997), rates of test result disclosure were similar for both populations; this suggests low rates of disclosure with primary care providers may persist over time. As time elapses, most breast cancer patients tested in the oncology care setting will transition into survivorship and their care will move back into the primary care setting [72]. Primary care physicians will assume more responsibility for prevention or risk management of secondary cancers in these patients. Thus, it is important to encourage breast cancer patients to share results with their primary care providers.

While our study presents important information about the frequency with which genetic information is shared with at-risk relatives and health care providers, findings should be considered in light of certain limitations. First, our sample size is small and did not allow for statistical analyses of differences in disclosure based on variables such as mutation status, gender of relative, or provider type. However, ours is the first study to focus on this issue exclusively among affected breast cancer patients and provides preliminary data to support larger studies focused on understanding and supporting disclosure of $B R C A$ test results among patients receiving counseling and testing at or near the time of a breast cancer diagnosis. Second, we evaluated sharing of test results during a relatively short time period $(\sim 5$ months post receipt of $B R C A$ test results). However, prior studies suggest that the majority of test result disclosures with firstdegree relatives occurs within weeks to a few months of when the proband receives their test results [43, 47]. Similarly, we observed consistent rates of communication with health care providers between our study and one that included breast cancer survivors who were several years from the time of testing [51]. This implies that if communication does not occur early, it will not likely occur later. Third, we did not assess detailed communication beyond firstdegree relatives. However, given that first-degree relatives are at highest risk for inheriting a $B R C A$ mutation and most likely to be informed by a proband's test results, we selected to focus on this group to minimize participant burden of a lengthy questionnaire that would be required to assess additional at-risk relatives. Our sample for the present study represents a subset of women from a larger study who remained in the study for the six-month assessment and were also willing to share test results. In this sense, selection bias should be considered when interpreting out results; it is possible that our results do not capture the full variability of disclosure patterns among women in this population. Finally, we did not directly assess whether patients had a previously identified $B R C A$ mutation in the family. Patients who were undergoing testing for a known family mutation may not need to communicate results with other at-risk relatives given this information may have already been provided by the initial relative who tested positive.

\section{Conclusion}

Communication of $B R C A$ test results is a critical step toward realizing the benefit of genetic technology to identify cancer risk both for individuals and family members. In light of current ethical and legal concerns regarding privacy of patient genetic information [71,73], probands are often responsible for sharing test results both to at-risk relatives and health care providers. Prior research suggests that, to a large extent, they are willing to accept and carry out that responsibility [74]. However, our study demonstrates key areas where breast cancer patients who choose to undergo GC and genetic testing may need further education and support to facilitate accurate and effective communication to inform at-risk family members' medical decisions and care while minimizing psychosocial burden and familial distress.

\section{Acknowledgments}

This research was conducted with funding from the American Cancer Society MRSG CPPB-111062. The work contained within this publication was supported in part by the Survey Methods Core Facility at Moffitt Cancer Center.

\section{References}

[1] Y. Miki, J. Swensen, D. Shattuck-Eidens et al., "A strong candidate for the breast and ovarian cancer susceptibility gene BRCA1," Science, vol. 266, no. 5182, pp. 66-71, 1994.

[2] R. Wooster, G. Bignell, J. Lancaster et al., "Identification of the breast cancer susceptibility gene BRCA2," Nature, vol. 378, no. 6559, pp. 789-792, 1995.

[3] S. Chen, E. S. Iversen, T. Friebel et al., "Characterization of BRCA1 and BRCA2 mutations in a large United States sample," Journal of Clinical Oncology, vol. 24, no. 6, pp. 863-871, 2006.

[4] O. Díez, J. Cortés, M. Domènech et al., "BRCA2 germ-line mutations in Spanish male breast cancer patients," Annals of Oncology, vol. 11, no. 1, pp. 81-84, 2000.

[5] D. F. Easton, L. Steele, P. Fields et al., "Cancer risks in two large breast cancer families linked to BRCA2 on chromosome 13q12-13," American Journal of Human Genetics, vol. 61, no. 1, pp. 120-128, 1997.

[6] D. Ford, D. F. Easton, M. Stratton et al., "Genetic heterogeneity and penetrance analysis of the BRCA1 and BRCA2 genes in breast cancer families," American Journal of Human Genetics, vol. 62, no. 3, pp. 676-689, 1998.

[7] A. Liede, I. A. Malik, Z. Aziz, P. De los Rios, E. Kwan, and S. A. Narod, "Contribution of BRCA1 and BRCA2 mutations to breast and ovarian cancer in Pakistan," American Journal of Human Genetics, vol. 71, no. 3, pp. 595-606, 2002. 
[8] H. A. Risch, J. R. McLaughlin, D. E. C. Cole et al., "Population BRCA1 and BRCA2 mutation frequencies and cancer penetrances: a kin-cohort study in Ontario, Canada," Journal of the National Cancer Institute, vol. 98, no. 23, pp. 1694-1706, 2006.

[9] Y. C. Tai, S. Domchek, G. Parmigiani, and S. Chen, "Breast cancer risk among male BRCA1 and BRCA2 mutation carriers," Journal of the National Cancer Institute, vol. 99, no. 23, pp. 1811-1814, 2007.

[10] D. Thompson and D. Easton, "Variation in cancer risks, by mutation position, in BRCA2 mutation carriers," American Journal of Human Genetics, vol. 68, no. 2, pp. 410-419, 2001.

[11] D. Easton, "Cancer risks in BRCA2 mutation carriers: the breast cancer linkage consortium," Journal of the National Cancer Institute, vol. 91, no. 15, pp. 1310-1316, 1999.

[12] H. Eerola, E. Pukkala, S. Pyrhnen, C. Blomqvist, R. Sankila, and H. Nevanlinna, "Risk of cancer in BRCA1 and BRCA2 mutation-positive and -negative breast cancer families (Finland)," Cancer Causes and Control, vol. 12, no. 8, pp. 739-746, 2001.

[13] O. Johannsson, N. Loman, T. Möller, U. Kristoffersson, Å. Borg, and H. Olsson, "Incidence of malignant tumours in relatives of BRCA1 and BRCA2 germline mutation carriers," European Journal of Cancer, vol. 35, no. 8, pp. 1248-1257, 1999.

[14] N. Loman, A. Bladström, O. Johannsson, A. Borg, and H. Olsson, "Cancer incidence in relatives of a population-based set of cases of early-onset breast cancer with a known BRCA1 and BRCA2 mutation status," $B C R$, vol. 5, no. 6, pp. R175R186, 2003.

[15] J. L. Bermejo and K. Hemminki, "Risk of cancer at sites other than the breast in Swedish families eligible for BRCA1 or BRCA2 mutation testing," Annals of Oncology, vol. 15, no. 12, pp. 1834-1841, 2004.

[16] R. Moslehi, W. Chu, B. Karlan et al., "BRCA1 and BRCA2 mutation analysis of 208 Ashkenazi Jewish women with ovarian cancer," American Journal of Human Genetics, vol. 66, no. 4, pp. 1259-1272, 2000.

[17] S. Thorlacius, S. Sigurdsson, H. Bjarnadottir et al., "Study of a single BRCA2 mutation with high carrier frequency in a small population," American Journal of Human Genetics, vol. 60, no. 5, pp. 1079-1084, 1997.

[18] H. Tulinius, J. E. Eyfjord, G. H. Olafsdottir et al., "The effect of a single BRCA2 mutation on cancer in Iceland," Journal of Medical Genetics, vol. 39, no. 7, pp. 457-462, 2002.

[19] C. J. Van Asperen, R. M. Brohet, E. J. Meijers-Heijboer et al., "Cancer risks in BRCA2 families: estimates for sites other than breast and ovary," Journal of Medical Genetics, vol. 42, no. 9, pp. 711-719, 2005.

[20] E. Warner, W. Foulkes, P. Goodwin et al., "Prevalence and penetrance of BRCA1 and BRCA2 gene mutations in unselected Ashkenazi Jewish women with breast cancer," Journal of the National Cancer Institute, vol. 91, no. 14, pp. 1241-1247, 1999.

[21] S. M. Edwards, Z. Kote-Jarai, J. Meitz et al., "Two percent of men with early-onset prostate cancer harbor germline mutations in the BRCA2 gene," American Journal of Human Genetics, vol. 72, no. 1, pp. 1-12, 2003.

[22] S. A. Gayther, K. A. F. De Foy, P. Harrington et al., "The frequency of germ-line mutations in the breast cancer predisposition genes BRCA1 and BRCA2 in familial prostate cancer," Cancer Research, vol. 60, no. 16, pp. 4513-4518, 2000.

[23] R. M. Giusti, J. L. Rutter, P. H. Duray et al., "A twofold increase in BRCA mutation related prostate cancer among Ashkenazi Israelis is not associated with distinctive histopathology," Journal of Medical Genetics, vol. 40, no. 10, pp. 787-792, 2003.
[24] T. Kirchhoff, N. D. Kauff, N. Mitra et al., "BRCA2 mutation in Icelandic prostate cancer patients," Clinical Cancer Research, vol. 10, no. 9, pp. 2918-2921, 2004.

[25] S. Sigurdsson, S. Thorlacius, J. Tomasson et al., "BRCA2 mutation in Icelandic prostate cancer patients," Journal of Molecular Medicine, vol. 75, no. 10, pp. 758-761, 1997.

[26] A. J. Willems, S. J. Dawson, H. Samaratunga et al., "Loss of heterozygosity at the BRCA2 locus detected by multiplex ligationdependent probe amplification is common in prostate cancers from men with a germline BRCA2 mutation," Clinical Cancer Research, vol. 14, no. 10, pp. 2953-2961, 2008.

[27] I. Agalliu, E. Karlins, E. M. Kwon et al., "Rare germline mutations in the BRCA2 gene are associated with early-onset prostate cancer," British Journal of Cancer, vol. 97, no. 6, pp. 826-831, 2007.

[28] A. M. Barsevick, S. V. Montgomery, K. Ruth et al., "Intention to communicate BRCA1/BRCA2 genetic test results to the family," Journal of Family Psychology, vol. 22, no. 2, pp. 303312, 2008.

[29] S. M. Domchek, T. M. Friebel, C. F. Singer et al., "Association of risk-reducing surgery in BRCA1 or BRCA2 mutation carriers with cancer risk and mortality," JAMA, vol. 304, no. 9, pp. 967-975, 2010.

[30] M. C. King, S. Wieand, K. Hale et al., "Tamoxifen and breast cancer incidence among women with inherited mutations in BRCA1 and BRCA2 national surgical adjuvant breast and bowel project (nsabp-p1) breast cancer prevention trial," JAMA, vol. 286, no. 18, pp. 2251-2256, 2001.

[31] S. A. Narod, J. S. Brunet, P. Ghadirian et al., "Tamoxifen and risk of contralateral breast cancer in BRCA1 and BRCA2 mutation carriers: a case-control study," The Lancet, vol. 356, no. 9245, pp. 1876-1881, 2000.

[32] M. Daly et al., The NCCN Genetic/Familial High-Risk Assessment: Breast and Ovarian Clinical Practice Guideline, version 1, 2009, http://www.nccn.org/professionals/physician gls/PDF/genetics_screening.pdf.

[33] R. Sifri, S. Gangadharappa, and L. S. Acheson, "Identifying and testing for hereditary susceptibility to common cancers," CA: A Cancer Journal for Clinicians, vol. 54, no. 6, pp. 309-326, 2004.

[34] J. Vos, A. M. Jansen, F. Menko, C. J. Van Asperen, A. M. Stiggelbout, and A. Tibben, "Family communication matters: the impact of telling relatives about unclassified variants and uninformative DNA-test results," Genetics in Medicine, vol. 13, no. 4, pp. 333-341, 2011.

[35] S. S. Bruinooge, "American Society of Clinical Oncology policy statement update: genetic testing for cancer susceptibility," Journal of Clinical Oncology, vol. 21, no. 12, pp. 2397-2406, 2003.

[36] ASHG Statement, "Professional disclosure of familial genetic information. The American Society of Human Genetics Social Issues Subcommittee on Familial Disclosure," American Journal of Human Genetics, vol. 62, no. 2, pp. 474-483, 1998.

[37] A. R. Bradbury, J. J. Dignam, C. N. Ibe et al., "How often do BRCA mutation carriers tell their young children of the family's risk for cancer? A study of parental disclosure of $B R C A$ mutations to minors and young adults," Journal of Clinical Oncology, vol. 25, no. 24, pp. 3705-3711, 2007.

[38] A. R. Bradbury, L. Patrick-Miller, B. L. Egleston et al., "When parents disclose BRCA1/2 test results: their communication and perceptions of offspring response," Cancer, vol. 118, no. 13, pp. 3417-3425, 2012.

[39] E. L. Cheung, A. D. Olson, T. M. Yu, P. Z. Han, and M. S. Beattie, "Communication of BRCA results and family testing 
in 1,103 high-risk women," Cancer Epidemiology Biomarkers and Prevention, vol. 19, no. 9, pp. 2211-2219, 2010.

[40] E. Claes, G. Evers-Kiebooms, A. Boogaerts, M. Decruyenaere, L. Denayer, and E. Legius, "Communication with close and distant relatives in the context of genetic testing for hereditary breast and ovarian cancer in cancer patients," American Journal of Medical Genetics, vol. 116, no. 1, pp. 11-19, 2003.

[41] E. Finlay, J. E. Stopfer, E. Burlingame et al., "Factors determining dissemination of results and uptake of genetic testing in families with known BRCA1/2 mutations," Genetic Testing, vol. 12, no. 1, pp. 81-91, 2008.

[42] C. Hughes, C. Lerman, M. Schwartz et al., "All in the family: evaluation of the process and content of sisters' communication about BRCA1 and BRCA2 genetic test results," American Journal of Medical Genetics, vol. 107, no. 2, pp. 143-150, 2002.

[43] A. F. Patenaude, M. Dorval, L. S. DiGianni, K. A. Schneider, A. Chittenden, and J. E. Garber, "Sharing BRCA1/2 test results with first-degree relatives: factors predicting who women tell," Journal of Clinical Oncology, vol. 24, no. 4, pp. 700-706, 2006.

[44] D. Gadzicki, L. U. Wingen, B. Teige et al., "Communicating BRCA1 and BRCA2 genetic test results," Journal of Clinical Oncology, vol. 24, no. 18, pp. 2969-2970, 2006.

[45] D. J. MacDonald, L. Sarna, G. Van Servellen, R. Bastani, J. N. Giger, and J. N. Weitzel, "Selection of family members for communication of cancer risk and barriers to this communication before and after genetic cancer risk assessment," Genetics in Medicine, vol. 9, no. 5, pp. 275-282, 2007.

[46] B. McGivern, J. Everett, G. G. Yager, R. C. Baumiller, A. Hafertepen, and H. M. Saal, "Family communication about positive BRCA1 and BRCA2 genetic test results," Genetics in Medicine, vol. 6, no. 6, pp. 503-509, 2004.

[47] J. Segal, M. J. Esplen, B. Toner, S. Baedorf, S. Narod, and K. Butler, "An investigation of the disclosure process and support needs of BRCA1 and BRCA2 carriers," American Journal of Medical Genetics, vol. 125, no. 3, pp. 267-272, 2004.

[48] J. W. Costalas, M. Itzen, J. Malick et al., "Communication of BRCA1 and BRCA2 results to at-risk relatives: a cancer risk assessment program's experience," American Journal of Medical Genetics, vol. 119, no. 1, pp. 11-18, 2003.

[49] C. Dancyger, M. Wiseman, C. Jacobs, J. A. Smith, M. Wallace, and S. Michie, "Communicating BRCA1/2 genetic test results within the family: a qualitative analysis," Psychology and Health, vol. 26, no. 8, pp. 1018-1035, 2011.

[50] D. Morgan, H. Sylvester, F. Lee Lucas, and S. Miesfeldt, "Hereditary breast and ovarian cancer: referral source for genetic assessment and communication regarding assessment with nongenetic clinicians in the community setting," Genetics in Medicine, vol. 12, no. 1, pp. 25-31, 2010.

[51] K. Ready, B. K. Arun, K. M. Schmeler et al., "Communication of BRCA1 and BRCA2 genetic test results to health care providers following genetic testing at a tertiary care center," Familial Cancer, vol. 10, no. 4, pp. 1-7, 2011.

[52] H. A. Hamann, T. J. Somers, A. W. Smith, S. S. Inslicht, and A. Baum, "Posttraumatic stress associated with cancer history and BRCA1/2 genetic testing," Psychosomatic Medicine, vol. 67, no. 5, pp. 766-772, 2005.

[53] C. Lerman, R. T. Croyle, K. P. Tercyak, and H. Hamann, "Genetic testing: psychological aspects and implications," Journal of Consulting and Clinical Psychology, vol. 70, no. 3, pp. 784-797, 2002.

[54] B. Meiser, "Psychological impact of genetic testing for cancer susceptibility: an update of the literature," Psycho-Oncology, vol. 14, no. 12, pp. 1060-1074, 2005.
[55] C. Julian-Reynier, F. Eisinger, F. Chabal et al., "Disclosure to the family of breast/ovarian cancer genetic test results: patient's willingness and associated factors," American Journal of Medical Genetics, vol. 94, no. 1, pp. 13-18, 2000.

[56] K. D. Valverde, "Why me? Why not me?" Journal of Genetic Counseling, vol. 15, no. 6, pp. 461-463, 2006.

[57] T. M. U. Wagner, R. Möslinger, G. Langbauer et al., "Attitude towards prophylactic surgery and effects of genetic counselling in families with BRCA mutations," British Journal of Cancer, vol. 82, no. 7, pp. 1249-1253, 2000.

[58] C. Cypowyj, F. Eisinger, L. Huiart, H. Sobol, M. Morin, and C. Julian-Reynier, "Subjective interpretation of inconclusive BRCA1/2 cancer genetic test results and transmission of information to the relatives," Psycho-Oncology, vol. 18, no. 2, pp. 209-215, 2009.

[59] N. Hallowell, C. Foster, A. Ardern-Jones, R. Eeles, V. Murday, and M. Watson, "Genetic testing for women previously diagnosed with breast/ovarian cancer: examining the impact of BRCA1 and BRCA2 mutation searching," Genetic Testing, vol. 6, no. 2, pp. 79-87, 2002.

[60] H. B. Mohamad and J. P. Apffelstaedt, "Counseling for male BRCA mutation carriers - a review," Breast, vol. 17, no. 5, pp. 441-450, 2008.

[61] M. B. Daly, J. E. Axilbund, S. Buys et al., "Genetic/familial high-risk assessment: breast and ovarian-clinical practice guidelines in oncology," JNCCN, vol. 8, no. 5, pp. 562-594, 2010.

[62] P. Borry, L. Stultiens, H. Nys, J. J. Cassiman, and K. Dierickx, "Presymptomatic and predictive genetic testing in minors: a systematic review of guidelines and position papers," Clinical Genetics, vol. 70, no. 5, pp. 374-381, 2006.

[63] A. R. Bradbury, L. Patrick-Miller, K. Pawlowski et al., "Learning of your parent's BRCA mutation during adolescence or early adulthood: a study of offspring experiences," PsychoOncology, vol. 18, no. 2, pp. 200-208, 2009.

[64] B. N. Peshkin, T. A. Demarco, and K. P. Tercyak, "On the development of a decision support intervention for mothers undergoing $B R C A 1 / 2$ cancer genetic testing regarding communicating test results to their children," Familial Cancer, vol. 9, no. 1, pp. 89-97, 2010.

[65] K. P. Tercyak, B. N. Peshkin, T. A. DeMarco, B. M. Brogan, and C. Lerman, "Parent-child factors and their effect on communicating BRCA1/2 test results to children," Patient Education and Counseling, vol. 47, no. 2, pp. 145-153, 2002.

[66] D. E. Levy, S. D. Byfield, C. B. Comstock et al., "Underutilization of $B R C A 1 / 2$ testing to guide breast cancer treatment: black and Hispanic women particularly at risk," Genetics in Medicine, vol. 13, no. 4, pp. 349-355, 2011.

[67] S. T. Vadaparampil, G. P. Quinn, C. A. Miree, J. Brzosowicz, B. Carter, and C. Laronga, "Recall of and reactions to a surgeon referral letter for BRCA genetic counseling among high-risk breast cancer patients," Annals of Surgical Oncology, vol. 16, no. 7, pp. 1973-1981, 2009.

[68] N. L. Keating, K. A. Stoeckert, M. M. Regan, L. DiGianni, and J. E. Garber, "Physicians' experiences with BRCA1/2 testing in community settings," Journal of Clinical Oncology, vol. 26, no. 35, pp. 5789-5796, 2008.

[69] L. Wideroff, A. N. Freedman, L. Olson et al., "Physician use of genetic testing for cancer susceptibility: results of a national survey," Cancer Epidemiology Biomarkers and Prevention, vol. 12, no. 4, pp. 295-303, 2003.

[70] L. Wideroff, S. T. Vadaparampil, M. H. Greene, S. Taplin, L. Olson, and A. N. Freedman, "Hereditary breast/ovarian and 
colorectal cancer genetics knowledge in a national sample of US physicians," Journal of Medical Genetics, vol. 42, no. 10, pp. 749-755, 2005.

[71] A. R. Patterson, L. D. Robinson, E. Z. Naftalis, B. B. Haley, and G. E. Tomlinson, "Custodianship of genetic information: clinical challenges and professional responsibility," Journal of Clinical Oncology, vol. 23, no. 9, pp. 2100-2104, 2005.

[72] C. F. Snyder, K. D. Frick, K. S. Peairs et al., "Comparing care for breast cancer survivors to non-cancer controls: a five-year longitudinal study," Journal of General Internal Medicine, vol. 24, no. 4, pp. 469-474, 2009.

[73] K. Offit, E. Groeger, S. Turner, E. A. Wadsworth, and M. A. Weiser, "The "duty to warn" a patient's family members about hereditary disease risks," JAMA, vol. 292, no. 12, pp. 1469 1473, 2004.

[74] L. S. Lehmann, J. C. Weeks, N. Klar, L. Biener, and J. E. Garber, "Disclosure of familial genetic information: perceptions of the duty to inform," American Journal of Medicine, vol. 109, no. 9, pp. 705-711, 2000. 


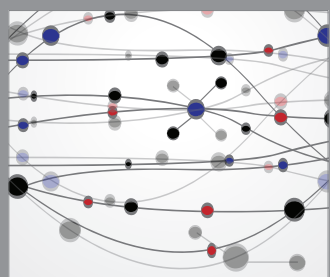

The Scientific World Journal
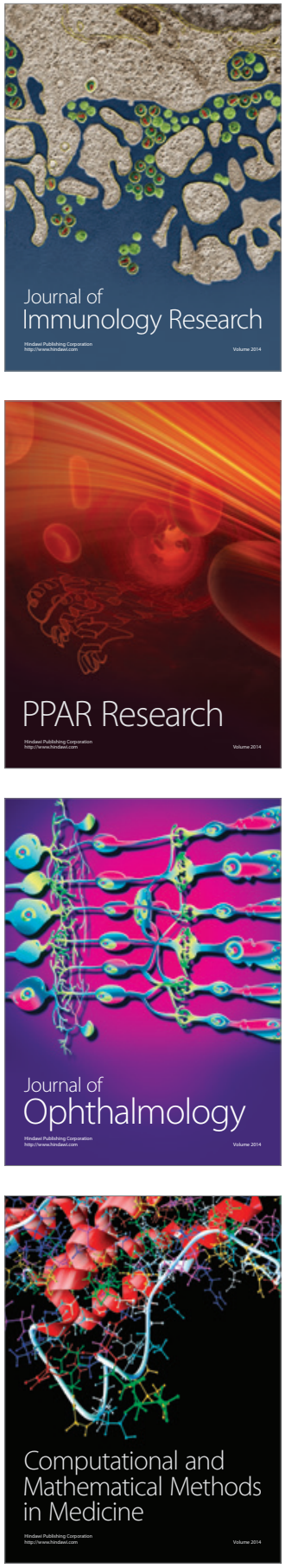

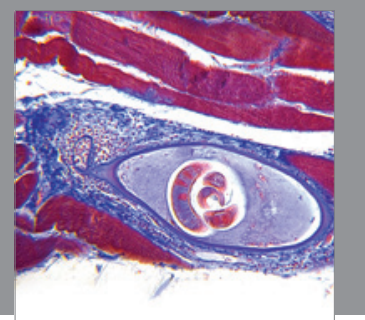

Gastroenterology

Research and Practice
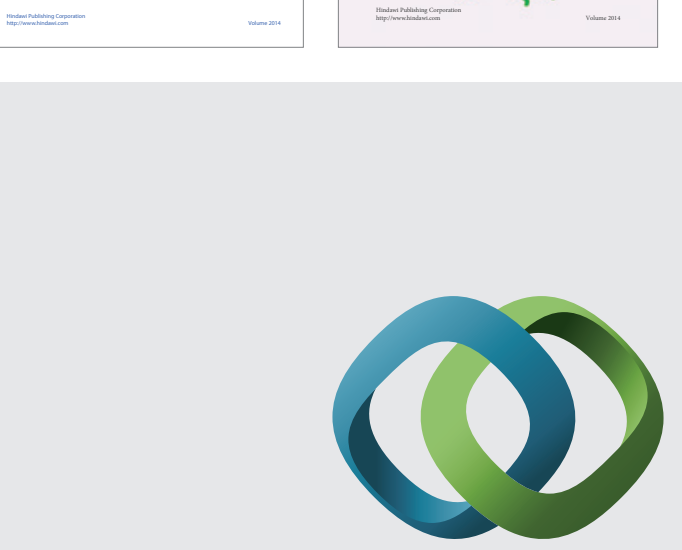

\section{Hindawi}

Submit your manuscripts at

http://www.hindawi.com
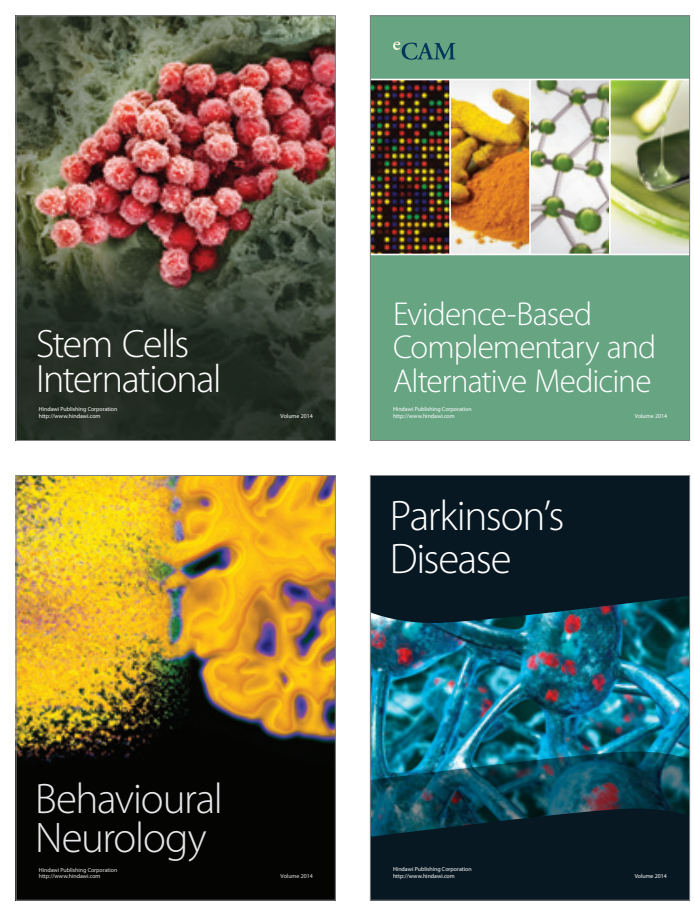

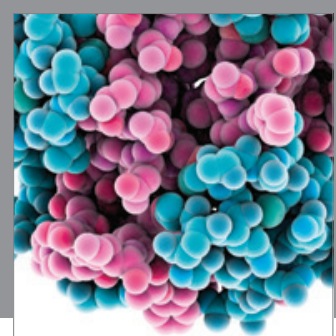

Journal of
Diabetes Research

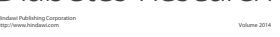

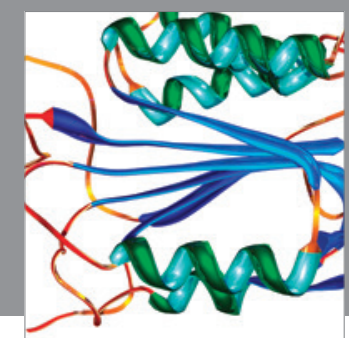

Disease Markers
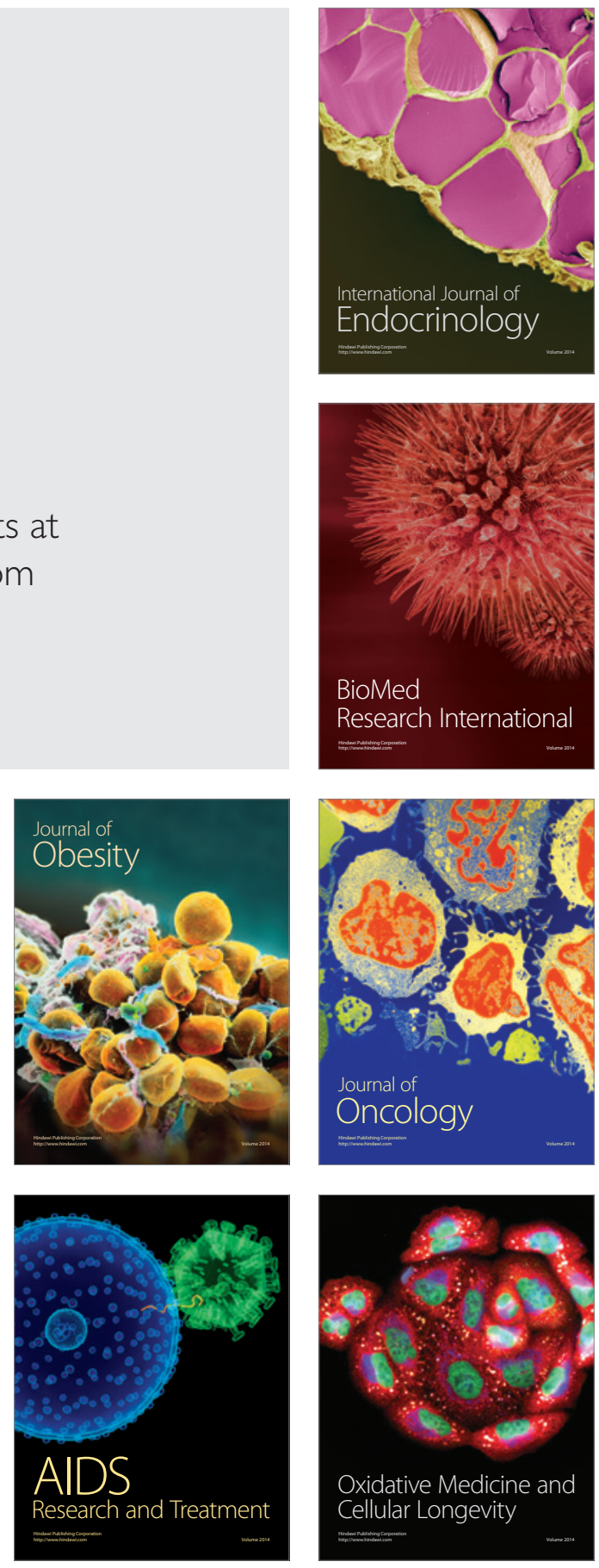